\title{
GREEN SYNTHESIS AND CHARACTERIZATION OF SILVER NANOPARTICLES FROM WITHANIA SOMNIFERA (L.) DUNAL
}

\author{
ANBALAGAN S ${ }^{1}$, SANKARESWARAN $\mathbf{M}^{1 *}$, PRABHAVATHI ${ }^{2}{ }^{2}$, MANIKANDAN ${ }^{3}$, KARTHIKEYAN G ${ }^{1}$ \\ ${ }^{1}$ Department of Microbiology, Muthayammal College of Arts and Science, Namakkal, Tamil Nadu, India. ${ }^{2}$ Department of Microbiology and \\ Biochemistry, NS College of Arts and Science, Theni, Tamil Nadu, India. ${ }^{3}$ Department of Microbiology, PSG College of Arts and Science,
} Coimbatore, Tamil Nadu, India. Email: sankarsankar87@gamil.com

Received: 02 June 2016, Revised and Accepted: 08 June 2016

\section{ABSTRACT}

The metal nanoparticle synthesis is highly explored the field of nanotechnology. The biological methods seem to be more effective because of slow reduction rate and polydispersity of the final products. The main aim of this study is too the rapid and simplistic synthesis of silver nanoparticles by Withania somnifera Linn. at room temperature. The exposure of reaction mixtures containing silver nitrate and dried leaf powder of $W$. somnifera resulted in reduction of metal ions within 5 minutes. The extracellular synthesized silver nanoparticles were characterized by ultraviolet-visible, infrared (IR) spectroscopy, X-ray diffraction studies, zeta potential, Fourier transform IR, and scanning electron microscopy. The antibacterial and antifungal studies showed significant activity as compared to their respective standards. From the results, $W$. somnifera sliver nanoparticle has attained the maximum antimicrobial against clinical pathogens and also seen very good stability of nanoparticle throughput processing. As we concluded, this type of naturally synthesized sliver nanoparticle could be a better green revolution in medicinal chemistry.

Keywords: Antimicrobial activity, Silver nanoparticles, Withania somnifera.

(C) 2016 The Authors. Published by Innovare Academic Sciences Pvt Ltd. This is an open access article under the CC BY license (http://creativecommons. org/licenses/by/4. 0/) DOI: http://dx.doi.org/10.22159/ajpcr.2016.v9i5.13204

\section{INTRODUCTION}

Green nanotechnology is an area with significant focus at present on the important objective of facilitating the manufacture of nanotechnology-based products that are eco-friendly and safer for all beings with sustainable commercial viability. The green synthesis of metal nanoparticles obtains great attention due to their unusual optical, chemical, photochemical, and electronic properties. The green synthesis of nanoparticles is an emerging branch of nanotechnology [1] The biosynthetic technique using plant extracts has received additional attention than chemical and physical methods and even the use of microbes. The method is suitable for nanoscale metal synthesis due to the absence of any requirement to maintain an aseptic environment.

The continuing appearance of antibiotic resistance in pathogenic and opportunistic microorganisms obliges the scientific community to constantly develop new drugs and drug targets. Few new antibiotics have been introduced by the pharmacy in the last decade, and none of them have improved the activity against multidrug-resistant bacteria [2] Because nanoparticles have demonstrated antimicrobial activities, the development of novel applications of antibiotic production.

Although the antimicrobial effects of silver derivatives are well documented, the mechanism by which it exerts its bioactivity is not known. Some reports have proposed the arrangement and evidence of silver-sulfur granules on the microbial cell wall, whereas other reports attribute its poisonous outcome of the inactivation of essential enzymes by forming complexes with the catalytic sulfur of thiol group in cysteine residues.

Withania somnifera (L.) dunal, commonly known in Sanskrit as ashwagandha, is a perennial plant belonging to the order Solanaceae. The plant has been found useful in the treatment of burns, wounds, and dermatological disorders [3]. The pharmacological effects of the roots of $W$. somnifera are attributed to the presence of with anolides, a group of steroidal lactones. Its leaves are used in Ayurvedic and Unani systems for the treatment of tumors and tubercular glands. The biological activities of $W$. somnifera are anxiolytic-anti-depressive [4], antifungal [5], antimalarial [6] apoptotic [7]. There are a number of reports elucidating the physicochemical and pharmacological properties of W. somnifera [8].

W. somnifera (Solanaceae) a traditional medicinal plant of tropical countries, including India, has the source of bioreductant and stabilizers. The current study was expected to synthesis of silver nanoparticles using aqueous root extract of $W$. somnifera as reducing agent against silver nitrate and also studied their antimicrobial activity against bacterial and fungal pathogens.

\section{METHODS}

Plant materials

Healthy roots of $W$. somnifera (Fig. 1) were collected from Kollihills and Namakkal district. The mature, undamaged and disease free-roots were selected and washed thoroughly with water using teepol and later washed out by sterile distilled water to remove the adhering dust and other contaminants. The roots were cut into small pieces $(1-2 \mathrm{~cm})$ dried at room temperature and ground into fine powders using kitchen blender.

\section{Preparation of root extract}

The root powder was sterilized at $121^{\circ} \mathrm{C}$ for 15 minutes. $25 \mathrm{~g}$ of powder was taken and mixed with $250 \mathrm{ml}$ of milli-Q water and kept in water bath $\left(80^{\circ} \mathrm{C}\right)$ for 10 minutes. Then, the extract was filtered with Whatman No: 1 filter paper. The filtrate extract was stored in refrigerator at $4^{\circ} \mathrm{C}$ for further use.

Preparation of silver nitrate solution

About $5 \mathrm{mM}$ silver nitrate solution was freshly prepared using sterile distilled water.

\section{Biosynthesis of silver nanoparticles}

- $\quad$ About $10 \mathrm{ml}$ of $W$. somnifera root extract was taken

- Add $90 \mathrm{ml}$ of $5 \mathrm{mM}$ silver nitrate to $10 \mathrm{ml}$ of root extracts for the reduction of silver ions

- After addition of root extract and $5 \mathrm{mM}$ silver nitrate solution, the mixture was incubated in dark condition (to minimize the photoactivation of silver nitrate) at room temperature 
- After the incubation the sample color change to brown. This color change indicates the synthesis of silver nanoparticles (Fig. 2)

- The ultraviolet (UV)-visible Spectrophotometer analysis was performed after $24 \mathrm{hrs}$ of incubation.

\section{Characterization of nanoparticles}

$U V$-visible spectrophotometer

UV-visible spectrum is one of the significant techniques to ascertain the formation of metal nanoparticles synthesized. The reduction of $\mathrm{Ag}^{+}$to $\mathrm{Ag}^{0}$ done by the root extract was recorded by UV-visible spectroscopy (ELICO BL 198 Biospectrophotometer) from 200 to $600 \mathrm{~nm}$.

\section{Fourier transform infrared (FTIR)}

A small aliquot of solution is used for the FTIR is performed to the extract. The spectrum was recorded using attenuated total reflectance technique. This was done using Perkin Elmer FTIR spectrophotometer, the scan range from $450 / \mathrm{cm}$ to $4000 / \mathrm{cm}$; The amino acid residues in polypeptides and proteins between amide linkages position give to wellknown signature in the IR region of the electromagnetic spectrum [9].

\section{$X$-ray diffraction $(X R D)$}

The crystalline metallic silver was confirmed by XRD. The XRD measurement of bioreduced silver nanoparticles was carried out using XRD analyzer. The silver nanoparticle solution obtained was purified by repeated centrifugation at $10,000 \mathrm{rpm}$ for 10 minutes followed by the pellet of silver nanoparticle was suspended in sterile distilled water.

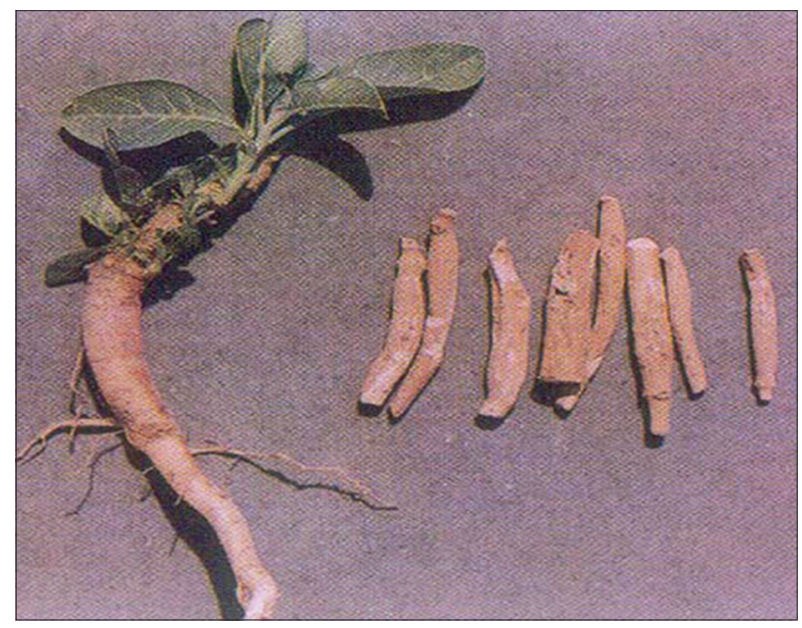

Fig. 1: Habitat of Withania somnifera plant with root

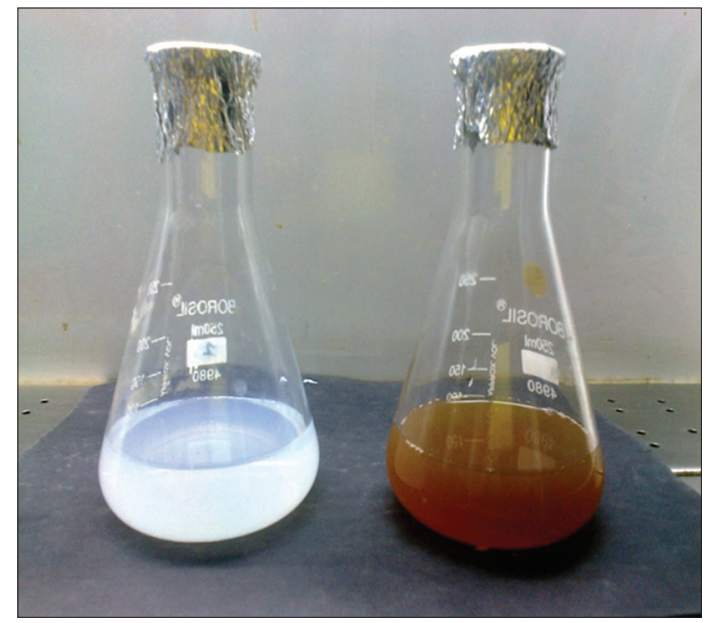

Fig. 2: Aqueous solution of $5 \mathrm{mM} \mathrm{AgNO}_{3}$ with Withania somnifera root extract
Further, the XRD measurements of the root broths synthesized silver nanoparticles solution were drop coated on XRD grid, and the spectra were recorded using Philips PW1830 X-ray generator operated at a voltage of $40 \mathrm{Kv}$ and a current of $30 \mathrm{~mA}$ with $\mathrm{Cu}, \mathrm{K} \alpha 1$ radiation in a $\theta-2 \theta$ configuration.

\section{Scanning electron microscopy (SEM)}

SEM was carried out using a JEOL, JAPAN, MODEL-6360 microscopy. The dried silver nanoparticles were freeze dried and their structure was analyzed by SEM. Thin film of the sample was prepared on a carbon coated copper grid by just dropping a very small amount of sample on the sample on the grid, extra solution was removed using isolating paper, and then, the film was allowed to dry putting it under a mercury lamp for 5 minutes the sample to be analyzed by the SEM [10].

\section{Dynamic light scattering (DLS)}

Size distribution of silver nanoparticles was measured using DLS (Zetasizer Nano ZS ZEN3600, Malvern, UK). From this measurement, the mean size of particles inside the sample is obtained along with the correlation between the number of particles of a particular size versus the size of the nanoparticles.

Screening of antimicrobial property in synthesized nanoparticles The antimicrobial activity was analyzed with synthesized silver nanoparticles by well diffusion method against bacteria: Gram-negative (Escherichia coli, Klebsiella species, Pseudomonas aeruginosa), Grampositive (Staphylococcus aureus), and fungi (Aspergillus niger and Candida albicans). In brief, the dried silver nanoparticles were weighed and dissolved $\left(5 \mathrm{mg} \mathrm{ml}^{-1}\right)$ in sterile distilled water.

\section{Preparation of bacterial inoculum}

Transfer 4-5 similar colonies with a needle to $5 \mathrm{ml}$ of peptone water and incubate at $37^{\circ} \mathrm{C}$ for $2-8 \mathrm{hrs}$ until light to moderate turbidity develops. Compare the inoculums turbidity with that of standard 0.5 McFarland.

\section{Preparation of fungal inoculum}

The inoculum is prepared by selecting 5 separate colonies from old cultures grown on sabouraud dextrose agar. The Mueller-Hinton agar plates were swabbed and approximately $7 \mathrm{~mm}$ diameter of well was made on plates with the help of gel puncture. About $50 \mu \mathrm{l}$ of silver nanoparticles was added into the well, also $5 \mathrm{mM} \mathrm{AgNO}_{3}$, root extracts, commercial antibiotic (ampicillin) for bacteria, and (amphotericin B) for fungi were added in other wells.

\section{RESULTS AND DISCUSSION}

\section{AgNPs synthesized by root extract}

\section{$U V$-visible spectroscopy}

The UV-visible spectrophotometer analysis is one of the majority broadly used simple technique for the observation of nanoparticles. The synthesized silver nanoparticle was analyzed in the range of 200-600 nm. It was observed that absorbance peak at $420 \mathrm{~nm}$ indicating reduction of $\mathrm{AgNO}_{3}$. As the extract was mixed with aqueous solution of silver nitrate, it started to modify the color from brown owed to the reduction of silver ions which indicate the formation of silver nanoparticles shown in Fig. 3. The peak at $210 \mathrm{~nm}$ was assigned to the strong absorption of peptide bond in the extract, and an absorption band at 260 and $280 \mathrm{~nm}$ is clearly visible and is attributed to electronic excitation in tyrosine, tryptophan, and phenylalanine residues in proteins. This indicates the release of extracellular proteins in the suspended aqueous solution and their promising mechanism in bioreduction process [11].

The formation of AgNPs by reduction of $\mathrm{AgNO}_{3}$ by W. somnifera root extract were determined using UV-visible spectroscopy and the weak surface plasmon resonance of AgNPs centered at $420 \mathrm{~nm}$. The similar results obtained from previously studied the synthesis of AgNPs 
using marine macroalga Chaetomorpha linum. Whereas, some other leaf extract which was already studied resultant peak at $420 \mathrm{~nm}$ that is synthesis of AgNPs by using Euphorbia prostrate [12] and Nelumbo nucifera [13]. Leaf extract of Ocimum sanctum had reduced Ag ions into AgNPs initially within 8 minutes of reaction time [14]. However, in the study, it was observed that the both fresh and dry flower extract had reduced $\mathrm{Ag}$ ions into AgNPs initially in 0 minutes of reaction time. Hence, it indicates this is the faster rate of AgNPs synthesis compared to the previous reports.

\section{FTIR}

The plant crude extract was used to prepare the nanoparticles and the synthesized product was checked with FTIR. The spectrum graphs of standard and sample showed the difference in peak areas confirmed the formation of nanoparticle. Absorption bands in spectrum graph of standard (before bio-reduction) are observed in the region of $450-4000 / \mathrm{cm}$ are $3914 / \mathrm{cm}, 3899 / \mathrm{cm}, 3839 / \mathrm{cm}, 3404 / \mathrm{cm}$, $2100 / \mathrm{cm}, 1648 / \mathrm{cm}, 1078 / \mathrm{cm}, 737 / \mathrm{cm}, 667 / \mathrm{cm}, 577 / \mathrm{cm}, 553 / \mathrm{cm}$, and $541 / \mathrm{cm}$ (Fig. 4). In sample (after bio-reduction), it shows intense peaks at $3364 / \mathrm{cm}, 2140 / \mathrm{cm}, 1645 / \mathrm{cm}$, and $744 / \mathrm{cm}$.

The plant crude extract was used to prepare the nanoparticles and the synthesized product was checked with FTIR. The FTIR capacity was agreed to conclude the biomolecules that specifically bound on the silver particles which are involved in the reduction, capping, and stabilization. FTIR spectra of $W$. somnifera root extract showed sharp absorption peaks at $3914 / \mathrm{cm}, 3899 / \mathrm{cm}, 3839 / \mathrm{cm}, 3404 / \mathrm{cm}, 2100 / \mathrm{cm}, 1648 / \mathrm{cm}$, $1078 / \mathrm{cm}, 737 / \mathrm{cm}, 667 / \mathrm{cm}, 577 / \mathrm{cm}, 553 / \mathrm{cm}$, and $541 / \mathrm{cm}$ (Fig. 4) and intense peaks were found at $3364 / \mathrm{cm}, 2140 / \mathrm{cm}, 1645 / \mathrm{cm}$, and $744 / \mathrm{cm}$ (Fig. 5). The spectrum graphs of standard and sample showed the difference in peak areas confirmed the formation of nanoparticle.

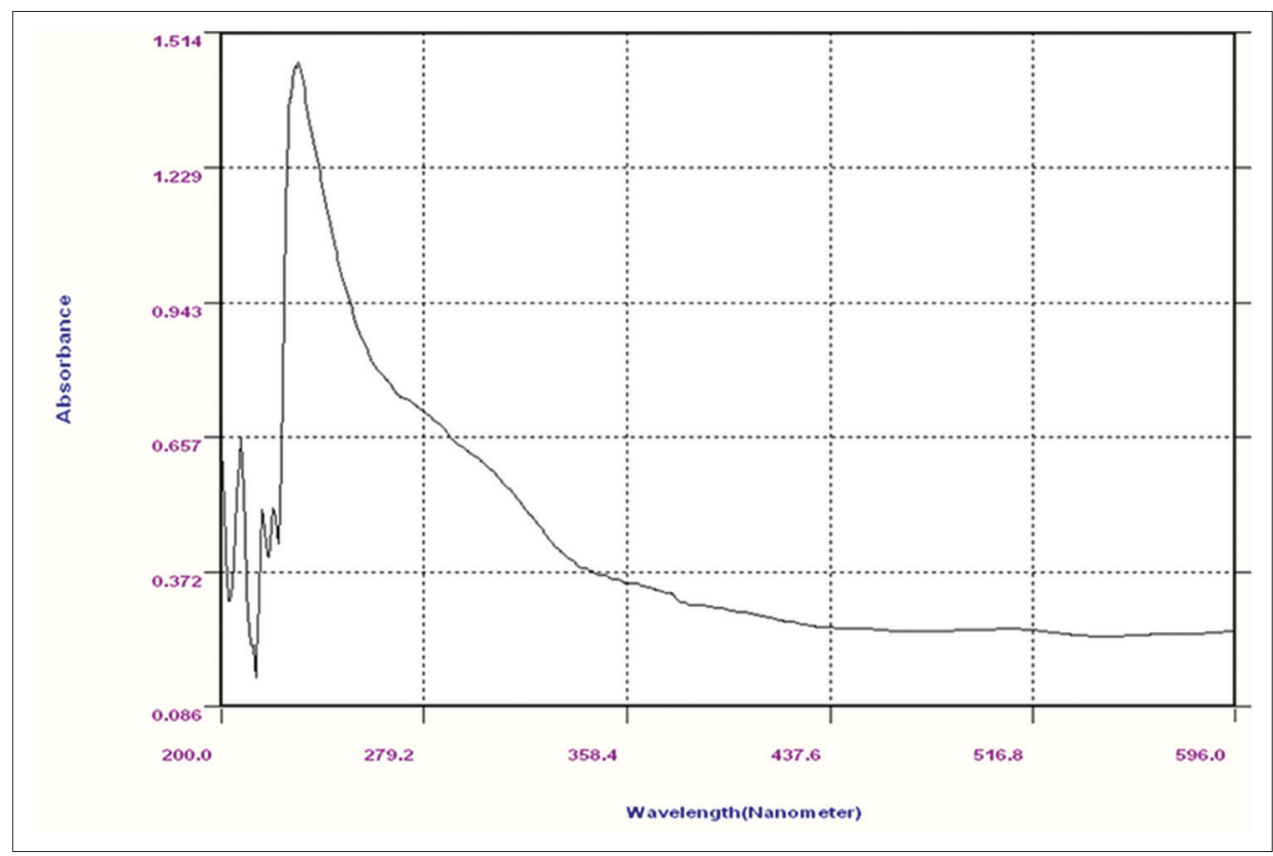

Fig. 3: Ultraviolet-visible spectrum analysis; plasmon resonance of silver nanoparticles reduced by Withania somnifera near at $420 \mathrm{~nm}$

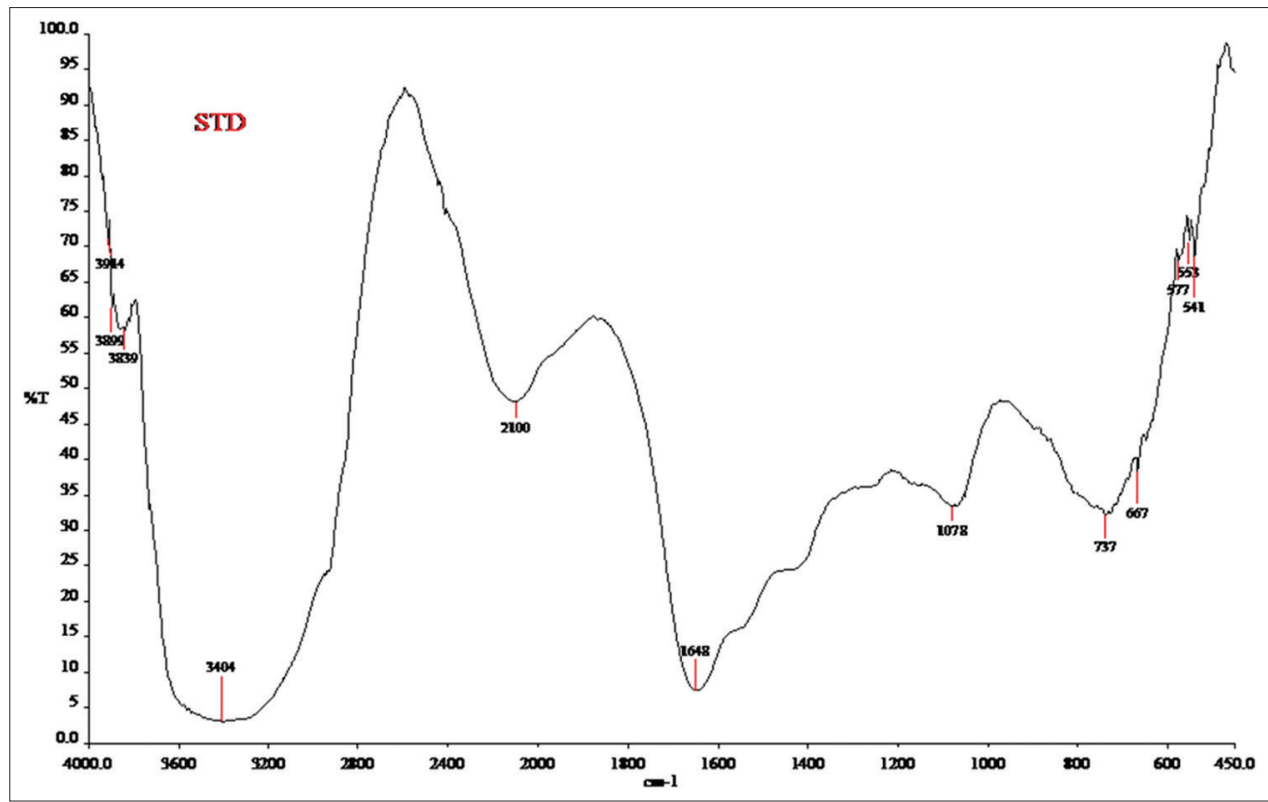

Fig. 4: Fourier transform infrared analysis for Withania somnifera root extract 


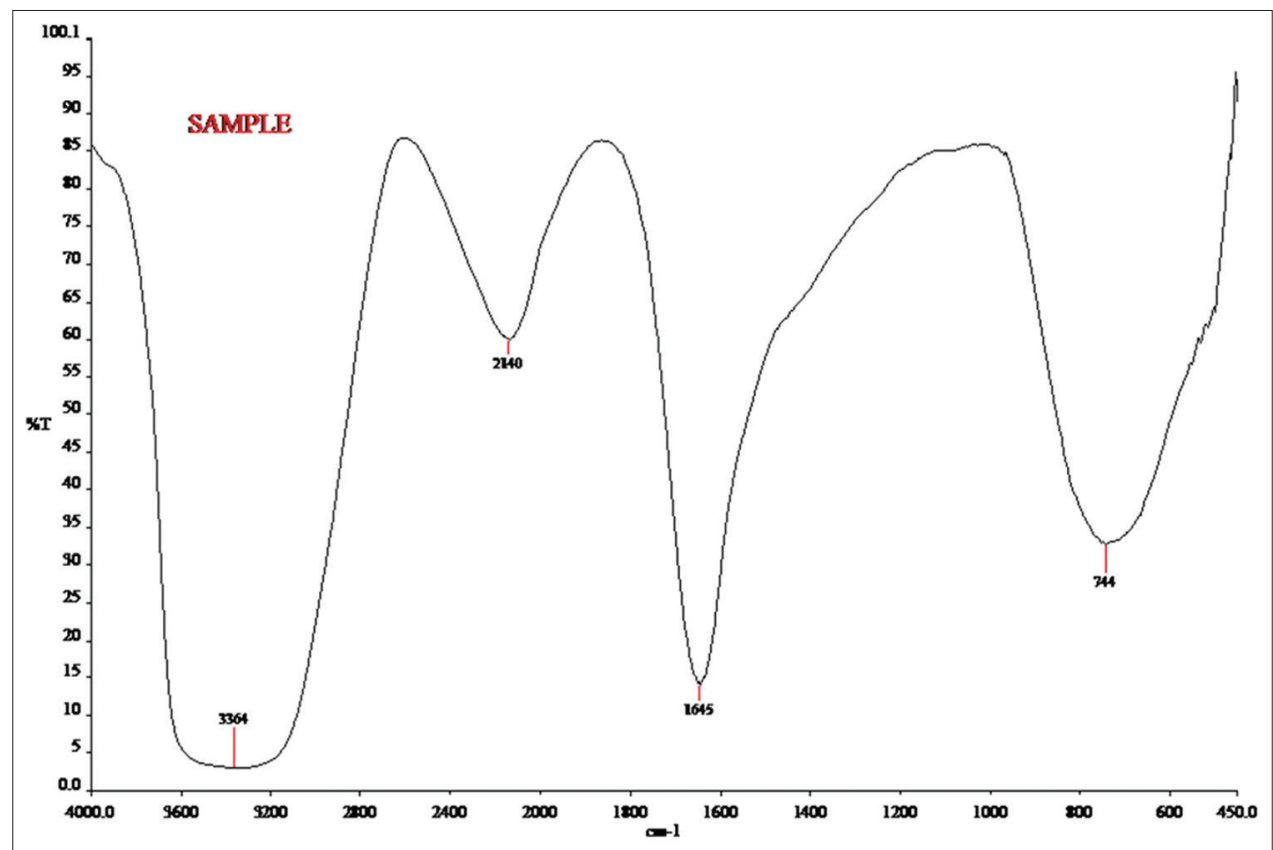

Fig. 5: Fourier transform infrared analysis for Withania somnifera root extract with silver nitrate solution

In the standard FTIR spectrum, a broad distorted peak area was observed in the region of $1600-1000 / \mathrm{cm}$ and in difference with the sample spectrum the similar region was disappeared. This is due to the presence of aliphatic or aromatic nitro groups, $\mathrm{N}-\mathrm{H}$ bend of amides or amines, the presence of $\mathrm{CH}_{3}$ and $\mathrm{CH}_{2}$ bending vibrations were noted in the region of $1470 / \mathrm{cm}$. The absence of the above peaks confirmed the elimination or alteration of respective group. Similarly, the stretching and bending vibrations of $\mathrm{C}=\mathrm{C}$ and $\mathrm{N}-\mathrm{H}$ groups from aromatic amines give the peak at $1600-1475 / \mathrm{cm}$. The sample peak at 3404 and $3364 / \mathrm{cm}$ is assigned to $\mathrm{OH}$ stretching in alcohols and phenolics compounds, $1645 / \mathrm{cm}$ indicates the $\mathrm{C}=\mathrm{H}$ stretch and alkene groups. The absorption peak at $1648 / \mathrm{cm}$ is close to native proteins are interacting with nanoparticles and also their secondary structures were not affected during reaction with silver ions [11]

\section{$X R D$}

XRD analysis showed three distinct diffraction peaks corresponding to face centered cubic structure of silver. Intense peaks were observed at $38.1^{\circ}, 44.1^{\circ}$ and $64.1^{\circ}$ (Fig. 6), corresponding to indexed the planes at 111,200 and 220. Bragg's reflection respectively. The broadening of the Bragg peaks indicates the formation of nanoparticles. Full width at half maximum data was used with Scherrer's formula [15] to determine the average particle size. The average particle size was estimated as $35 \mathrm{~nm}$.

The results of XRD pattern further confirm the synthesis of silver nanoparticles with sharp bands of Bragg peaks, and this might due to the stabilization of the nanoparticles by a mixture of reducing agents of the $W$. somnifera root extract and thus provides the crystalline nature of the silver nanoparticles [16]. This clearly illustrates that silver nanoparticles synthesized by green method were nanocrystalline in nature.

\section{$D L S$}

The DLS pattern reveals that silver nanoparticles were synthesized by this method have a zeta average diameter of $1.099 \mathrm{~nm}$ with polydispersity index of 0.231 and intercept of 0.858 (Fig. 7). Particle size determinations of the formulated nanoparticles were shown under different categories such as size distribution by degree and strength. The formed silver nanoparticles are well distributed with respect to degree and strength is a suggestion of the configuration of well-built silver nanoparticles and their polydispersity.

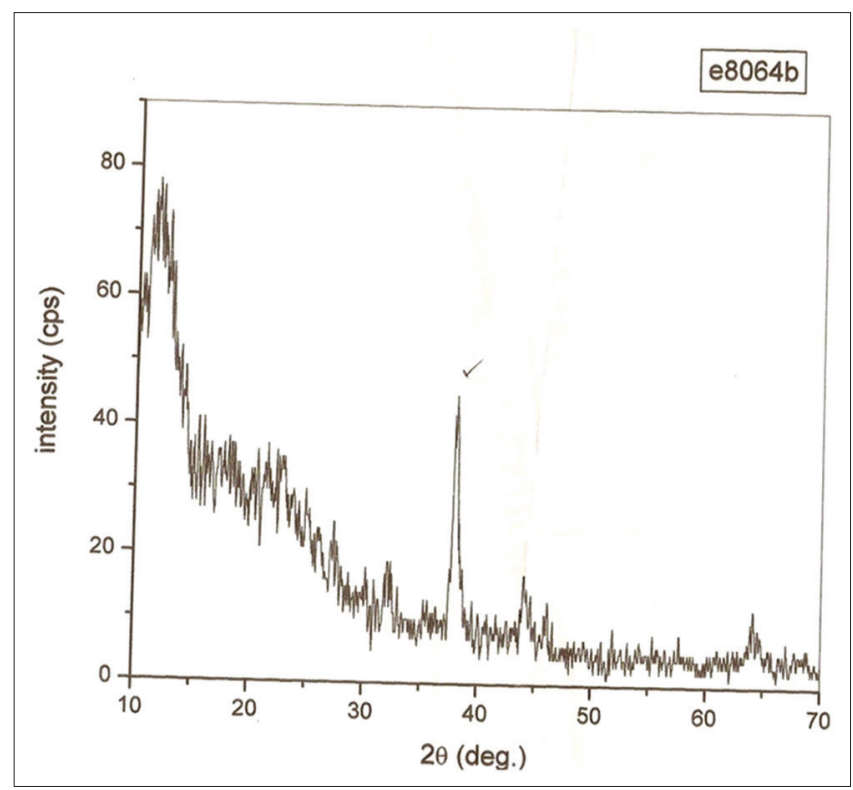

Fig. 6: X-ray diffraction pattern of biosynthesized silver nanoparticles

SEM

SEM micrograph analysis finally confirmed the synthesis of silver nanoparticles in the reaction mixture. At room temperature, the addition of $5 \mathrm{mM}$ aqueous silver nitrate solution to the root extract caused the precipitation of nanoparticle. These precipitates are observed under microscopic studies for the nanoparticles surface morphology. SEM analysis of the silver nanoparticles shows various sizes of the particles. It is clear from the SEM pictures that silver nanoparticles particles in the bioreduced colloidal suspensions measured $63.5-113 \mathrm{~nm}$ in size. The morphology of the nanoparticles was spherical (Fig. 8).

The synthesized silver nanoparticles were clearly distinguishable measured 63.5-113 nm in size. Most of the nanoparticles were roughly circular in shape with smooth edges. These structures were identical with that of the silver nanoparticles formed as of the sun-dried leaf 
powder of Cinnamomum camphora, which was accredited to a similarity in the reductive agents present in both plant species [17].

\section{Antimicrobial efficacies of synthesized nanoparticles}

The antimicrobial activity of the AgNPs against bacterial and fungal pathogens was observed after incubation $\left(37^{\circ} \mathrm{C}\right)$. The growth suppression was observed in plates loaded with $50 \mu \mathrm{l}$ of AgNPs. The bacterial and fungal growth inhibition around the well is due to the release of diffusing inhibitory compounds from the AgNPs [18]. It was observed that silver nanoparticles of $W$. somnifera root extract have showed highest activity of bacterial inhibition toward Gram-negative bacteria P. aeruginosa $(20 \mathrm{~mm})$, Klebsiella species $(16 \mathrm{~mm})$, E. coli (14 $\mathrm{mm})$ followed by Gram-positive bacteria S. aureus $(11 \mathrm{~mm})$ and

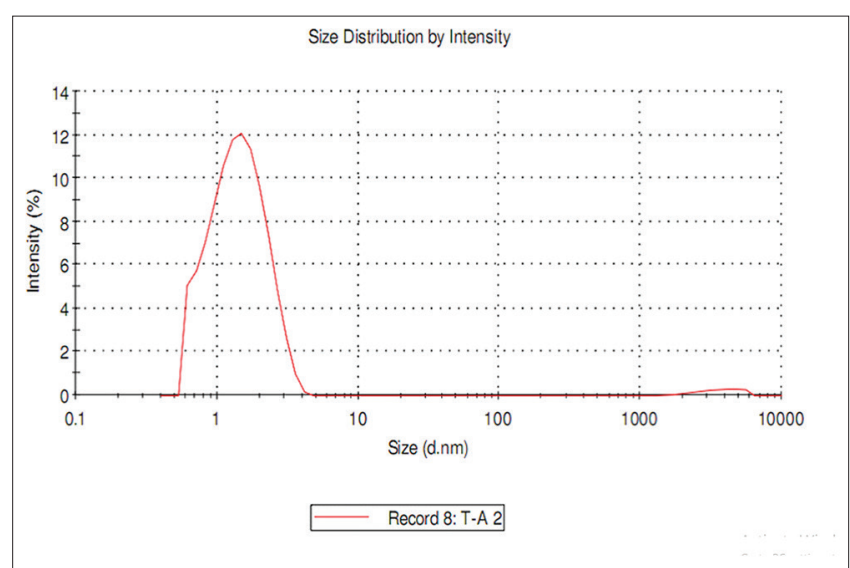

Fig. 7: Particle size distribution of AgNPs by intensity with zeta analyzer

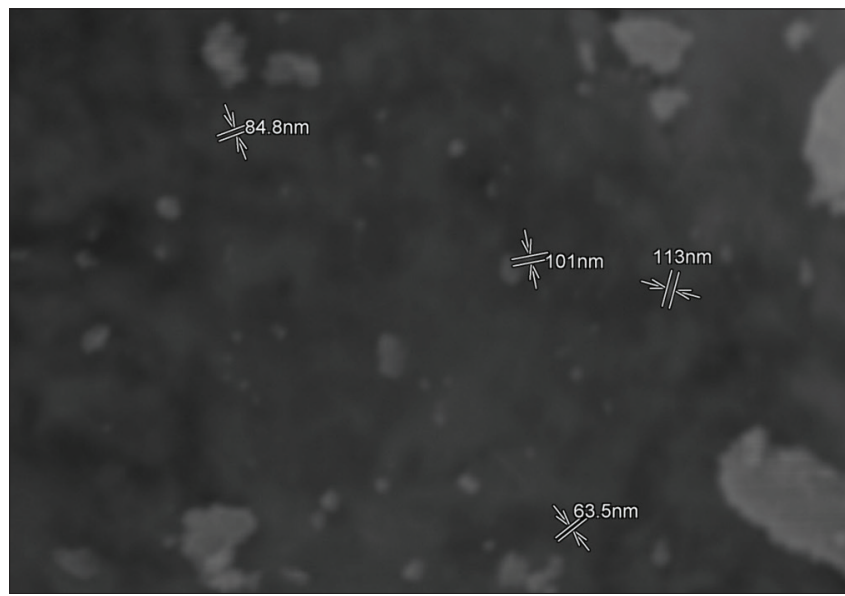

Fig. 8: Scanning electron microscope image of silver nanoparticles synthesized with Withania somnifera root extract and $5 \mathrm{mM}$ $\mathrm{AgNO}_{3}$ antifungal activity against $A$. niger $(17 \mathrm{~mm})$ followed by $C$. albicans (14 mm) (Table 1). The reason that the lesser size of the particles which leads to increased membrane permeability and cell destruction. The results were compared to that of antibiotics (ampicillin/ amphotericin-B) antibacterial and antifungal. Standard drugs (ampicillin/amphotericin-B) showed higher inhibition zones because these are highly purified forms which may be cost and leads to side effects in high dosage, whereas the AgNPs are biologically synthesized form with less in cost, eco-friendly, safe and pollutant free with less or no side effects. In root extract was not found any of antimicrobial patterns (Fig. 9).

\section{CONCLUSIONS}

In summary, a novel and rapid method for extracellular synthesis of metallic silver nanoparticles using aqueous root extracts of $W$. somnifera were demonstrated. The reduction of metal ions by leaf extracts loading

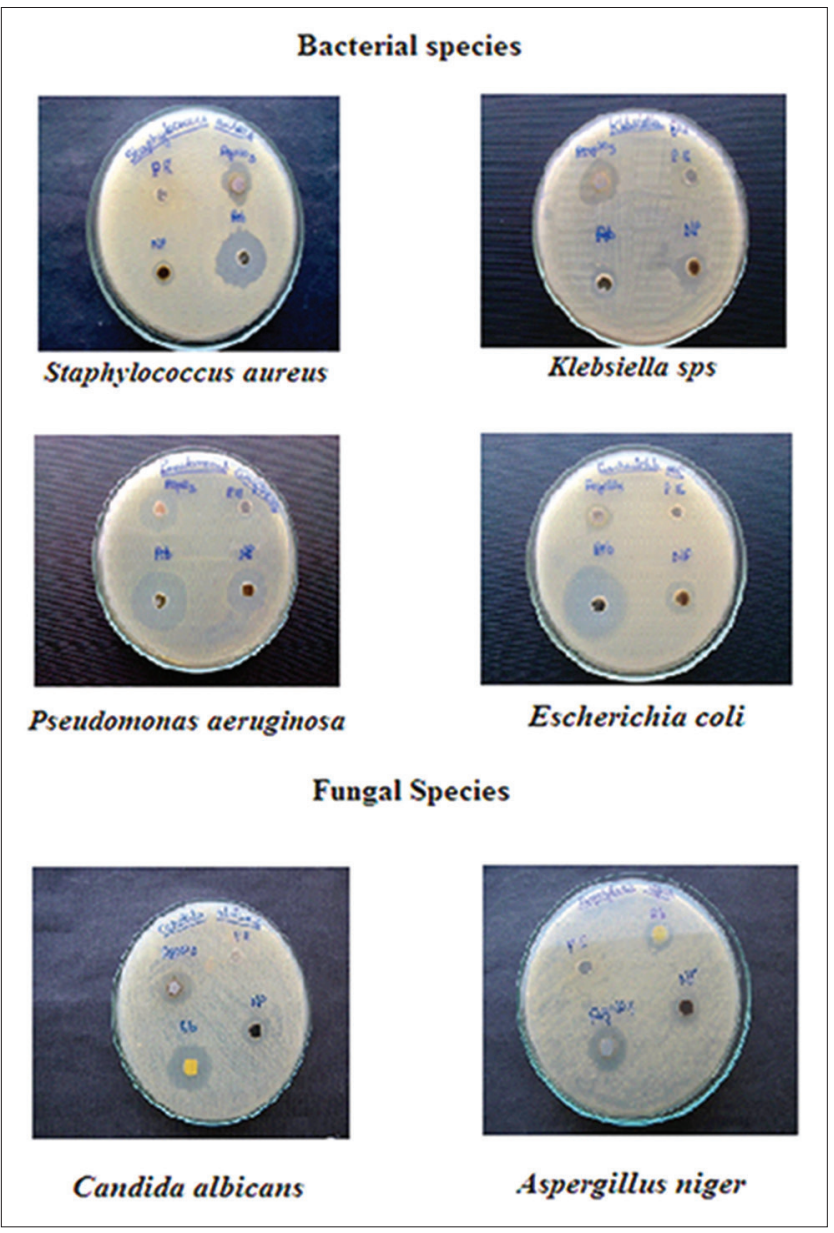

Fig. 9: Antimicrobial activity of Withania somnifera root extract

Table 1: Antimicrobial activity of metallic silver nanoparticles synthesized by using Withania somnifera root extract

\begin{tabular}{|c|c|c|c|c|}
\hline \multirow[t]{2}{*}{ Microorganisms } & \multicolumn{4}{|c|}{ Zone of inhibition (mm) $(50 \mu \mathrm{l} /$ well $)$} \\
\hline & $5 \mathrm{~mm} \mathrm{AgNO}_{3}$ & Antibiotics $(10 \mathrm{mg} / \mathrm{ml})$ & Root extract $(10 \mathrm{mg} / \mathrm{ml})$ & AgNPs $(10 \mathrm{mg} / \mathrm{ml})$ \\
\hline \multicolumn{5}{|l|}{ Bacterial species } \\
\hline Staphylococcus aureus (mm) & 15 & 24 & - & 11 \\
\hline Escherichia coli $(\mathrm{mm})$ & 11 & 34 & - & 14 \\
\hline Klebsiella sps (mm) & 15 & 10 & - & 16 \\
\hline Pseudomonas aeruginosa $(\mathrm{mm})$ & 13 & 25 & - & 20 \\
\hline \multicolumn{5}{|l|}{ Fungal species } \\
\hline Candida albicans $(\mathrm{mm})$ & 18 & 20 & - & 14 \\
\hline Aspergillus niger (mm) & 20 & 14 & - & 17 \\
\hline
\end{tabular}


silver nanocomposites of quite distinct proportions. However, the capabilities of some other plant parts like root is not tested and not well defined. Applications of such eco-friendly nanoparticles in bactericidal, lesion healing and other medical and electronic applications, makes this method potentially exciting for the large-scale synthesis of other inorganic materials (nanomaterials). The synthesized silver nanoparticles were characterized by UV-visible spectra, FTIR and SEM. Based on the current conclusion, it is accomplished that silver nanoparticles could be used as an antifungal agent in controlling the disease caused by fungi. The present study has opened up the possible way for synthesizing multidrug-resistant antimicrobial AgNPs using natural biomolecules which could be employed in the pharmacy industry. Hence, the biological approach appears to be simple, costefficient and rapid green synthesis alternative to conventional physical and chemical methods of silver nanoparticles synthesis and would be appropriate for mounting a biological process for large-scale production. By using such plant extracts to develop nanomedicine along idea variety of human and other veterinary pathogens.

\section{REFERENCES}

1. Roy N, Barik A. Green synthesis of silver nanoparticles from the unexploited weed resources. Int J Nanotechnol 2010;4:95.

2. Conlon JM, Kolodziejek J, Nowotny N. Antimicrobial peptides from ranid frogs: Taxonomic and phylogenetic markers and a potential source of new therapeutic agents. Biochim Biophys Acta 2004;1696(1):1-14.

3. Grierson DS, Afolayan AJ. Antibacterial activity of some indigenous plants used for the treatment of wounds in the Eastern Cape, South Africa. J Ethnopharmacol 1999;66(1):103-6.

4. Bhattacharya SK, Bhattacharya A, Sairam K, Ghosal S. Anxiolyticantidepressant activity of Withania somnifera glycowithanolides: An experimental study. Phytomedicine 2000;7(6):463-9.

5. Girish KS, Machiah KD, Ushanandini S, Harish Kumar K, Nagaraju S, Govindappa $\mathrm{M}$, et al. Antimicrobial properties of a non-toxic glycoprotein (WSG) from Withania somnifera (Ashwagandha). J Basic Microbiol 2006;46(5):365-74.

6. Dikasso D, Makonnen E, Debella A, Abebe D, Urga K, Makonnen W, et al. Anti-malarial activity of Withania somnifera L. Dunal extracts in mice. Ethiop Med J 2006;44(3):279-85

7. Senthil V, Ramadevi S, Venkatakrishnan V, Giridharan P, Lakshmi BS, Vishwakarma RA, et al. Withanolide induces apoptosis in HL-60 leukemia cells via mitochondria mediated cytochrome c release and caspase activation. Chem Biol Interact 2007;167(1):19-30.

8. Kandil FE, Elsayeh NH, Abou-Douh AM, Ishak MS, Mabry TJ. Phytochemistry. ??? 1994;37:1215-6.

9. Chandran SP, Chaudhary M, Pasricha R, Ahmad A, Sastry M. Synthesis of gold nanotriangles and silver nanoparticles using Aloe vera plant extract. Biotechnol Prog 2006;22(2):577-83.

10. Khandelwal N, Singh A, Jain D, Upadhyay MK, Verma HN. Green synthesis of silver nanoparticles using Argimone mexicana leaf extract and evaluation of their antiomicrobial activities. J Nanomater Biostrct 2010;5(2):483-9.

11. Fayaz AM, Balaji K, Girilal M, Yadav R, Kalaichelvan PT, Venketesan R. Biogenic synthesis of silver nanoparticles and their synergistic effect with antibiotics: A study against gram-positive and gram-negative bacteria. Nano Med 2010;6(1):103-9.

12. Zahir AA, Bagavan A, Kamaraj C, Elango G, Rahuman AA. Efficacy of plant-mediated synthesized silver nanoparticles against Sitophilus oryzae. J Biopest 2012;5:95-102.

13. Santhoshkumar T, Kirthi AV, Jayaseelan C, Bagavan A, Zahir AA, Elango G, et al. Evaluation of green synthesized silver nanoparticles against parasites. Parasitol Res 2001;108:1541-9.

14. Sighal G, Bhavesh R, Kasariya K, Sharma AR, Singh RP. Biosynthesis of silver nanopaticles using Ocimum sanctum (Tulsi) leaf extract and screening its antimicrobial activity. J Nnaopart Res 2011;13:2981-8.

15. Klug HP, Alexander LE. X-ray Diffraction Procedures for Polycrystalline and Amorphous Materials. New York: Wiley; 1967.

16. Nabikhan A, Kandasamy K, Raj A, Alikunhi NM. Synthesis of antimicrobial silver nanoparticles by callus and leaf extracts from saltmarsh plant, Sesuvium portulacastrum L. Colloids Surf B Biointerfaces 2010;79(2):488-93.

17. Huang J, Li Q, Sun D, Lu Y, Su Y, Yang X, et al. Biosynthesis of silver and gold nanoparticles by novel sundried Cinnamomum camphora leaf. Nanotechnol 2007;18:105104-14.

18. Kora AJ, Sashidhar RB, Arunachalam J. Gum kondagogu (Cochlospermum gossypium), a template for the green synthesis and stabilization of silver nanoparticles with antibacterial application. J Carbohydr Polym 2010;82:670-9. 